\title{
The Prevalence of Pseudomonas aeruginosa among Baghdad Hospitalised Patients
}

\author{
Heba K. Tawfeeq ${ }^{1}$, Muthanna Hamid ${ }^{2}$, Harith Jabbar Fahad Al-Mathkhury ${ }^{3}$ \\ ${ }^{1}$ Assistant Lecturer, Department of Biology, College of Science, University of Anbar, Anbar, Iraq, Department \\ of Biology, College of Science, University of Baghdad, Baghdad, Iraq, ${ }^{2}$ Assistant Professor, Assistant Lecturer, \\ ${ }^{1}$ Department of Biology, College of Science, University of Anbar, Anbar, Iraq, ${ }^{3}$ Professor, Department of Biology, \\ College of Science, University of Baghdad, Baghdad, Iraq
}

\begin{abstract}
In order to determine the prevalence of Pseudomonas aeruginosa among hospitalised patients, 156 specimens were collected from hospitalized patients referring Baghdad, Iraq hospitals. Bacterial isolates were identified using conventional biochemical tests and then identification was confirmed by the locating of 16SrRNA. Pseudomonas aeruginosa constitutes $30.05 \%$. In conclusion, the attention should be paid toward the infections of this opportunistic pathogen.
\end{abstract}

Keywords: Pseudomonas aeruginosa, hospital, 16SrRNA, PCR.

\section{Introduction}

Pseudomonas aeruginosa is a Gram-negative bacterium that is ubiquitous in different ecosystems and involves in numerous forms of relations with eukaryotic host. It is an opportunistic pathogen extensively spread in humans and animals (1), leading to a wide range of infections in community and hospitals ${ }^{(2,3)}$. Due to the extended spread of $P$. aeruginosa habitat, the control of the organism in a hospital setting is very difficult, and makes it practically impossible to prevent contamination ${ }^{(4)}$. The major threat is the infection of immunocompromised patients or those in burns, neonatal and cancer wards ${ }^{(5)}$. Infection of $P$. aeruginosa is still one of the main causes of death among the critically ill and patients with impaired immune systems in spite of the development of newer and stronger antibiotics ${ }^{(6)}$.

Due to the extended spread of $P$. aeruginosa habitat, the control of the organism in a hospital setting is very difficult, and makes it practically impossible to prevent contamination. The major threat is the infection of patients who are immunocompromised or those in burns, neonatal, cancer wards, it is the main cause of morbidity and mortality in cystic fibrosis patients and one of the leading nosocomial pathogens affecting hospitalized patients ${ }^{(7)}$.

Due to the innate capacity of resistance to antimicrobial agents, this bacterium is greatly difficult to treat. What's more, such resistance is being progressively a problematic issue because of increasingly development of resistance to agents regarded as powerful therapeutic options ${ }^{(8)}$.

In this study we have used a genus specific bacterial 16S PCR to investigate the prevalence and diversity of $P$. aeruginosa among Iraqi hospitalised patients.

\section{Materials and Method}

Ethical Statement: All participants agreed to provide the investigator with the specimens. Informed consent according to the Declaration of Helsinki was obtained from all participants.

Pseudomonas aeruginosa isolation and identification: One hundred and fifty-six specimens included mid-stream urine, burn swabs, wound swabs, and blood were collected from hospitalized patients referring Al-Yarmouk teaching Hospital and Baghdad Medical City in Baghdad, Iraq. All specimens were cultured on enrichment media such as blood agar and transferred onto MacConkey agar. Pale colonies on MacConkey agar (lactose non-fermenter) were assayed for the conventional morphological and biochemical characterization comprising Gram stainability was conducted alongside the activities of oxidase and 
catalase. Thereafter the primarily identified $P$. aeruginos isolates were submitted to molecular identification by polymerase chain reaction (PCR) technique.

\section{Detection of 16SrRNA}

Extraction of Bacterial DNA: Genomic DNA was extracted using Presto $^{\text {TM }}$ Mini gDNA Bacteria (Geneaid, Thailand). Upon the procedure itemized by the manufacturing company, DNA was extracted from overnight cultures of the carefully chosen staphylococcal isolates. Purified DNA concentration was measured using Biodrop (Biodrop, Canada).

PCR: To confirm the identification of $P$. aeruginosa isolates, conventional PCR technique was carried out in accordance to Spilker et al. ${ }^{(9)}$ to amplify a fragment of 16SrRNA (956 bp). Two microliters of each primer PASS-F (5'-GGGGGATCTTCGGACCTCA-3') and PASS-R (5'-TCCTTAGAGTGCCCACCCG-3'), different concentrations of DNA (depending on DNA yield) extracted from each $P$. aeruginosa isolate and deionized D.W. were added to PCR premix tubes (Bioneer, Korea) in order to reach $20 \mu \mathrm{l}$ as a final volume. The thermocycling conditions (Bio-Rad T100, USA) set at $94^{\circ} \mathrm{C}$ for $2 \mathrm{~min}$, followed by 25 cycles of $94^{\circ} \mathrm{C}$ for $20 \mathrm{~s}$, $58^{\circ} \mathrm{C}$ for $20 \mathrm{~s}$, and $72^{\circ} \mathrm{C}$ for $40 \mathrm{~s}$. A final extension of 1 min at $72^{\circ} \mathrm{C}$ was applied. PCR products were visualized using $2 \%$ agarose gel stained with diamond nucleic acid dye (Promega, USA).

\section{Results}

Isolation and identification: A total of 52 (33.33\%) isolates developed a growth on cetrimide agar, pale colonies on MacConkey agar, and succeeded to grow on nutrient agar at $42^{\circ} \mathrm{C}$. Moreover, they were oxidase and catalase positive. Hence, these isolates were primarily identified as $P$. aeruginosa.

DNA extraction and preparation: After DNA extraction by Presto ${ }^{\mathrm{TM}}$ Mini gDNA Bacteria Kit, DNA concentration was between 24 and $78 \mathrm{ng} / \mathrm{ml}$; whereas, purity was about 1.82-1.99. A ratio of 1.8 -2.0 is generally accepted as "pure" for DNA ${ }^{(10)}$. Gel electrophoresis was done to confirm the integrity of extracted DNA.

Molecular Detection: The current results revealed that $16 \operatorname{SrRNA}$ was located in $50(96.1 \%)$ out of 52 biochemically $P$. aeruginosa isolates. Correspondingly, two isolates were identified using traditional method as $P$. aeruginosa, they did not have this gene.

\section{Discussion}

Pseudomonas aeruginosa is an opportunistic pathogen capable of causing a wide array of life threatening acute and chronic infections particularly in patients with compromised immune defense (11). Earlier reports have shown that the antibiotic resistance of bacteria due to biofilm formation contributes to the persistence of bacterial cells and causes problems in the complete eradication of infection ${ }^{(12,13)}$.

The present work is in agreement with ${ }^{(14)}$ as they found that the results of $16 S r R N A$ showed that all $P$. aeruginosa isolates were resistance to gentamicin harbored this gene. Al-Derzi ${ }^{(15)}$ stated that out of 8038 and 1878 clinical specimens submitted for culture in Mosul and Duhok, respectively, 180 and 21 clinically significant isolates of $\mathrm{P}$. aeruginosa were isolated, resulting in a prevalence of $5.2 \%$ and $1.6 \%$, respectively. Moreover, cultural and biochemical identification revealed that $63 P$. aeruginosa isolates were recovered from 158 samples in Karbala, Iraq ${ }^{(16)}$. Also Hasan et al. ${ }^{(17)}$ reported that $21.6 \%$ P. aeruginosa isolates were collected form 185 swab samples in Kirkuk City, Iraq.

The variability in $P$. aeruginos $a$ isolation percentage may be attributed to geographic, climatic, and hygienic factors among different areas. As well as, the high prevalence of $P$. aeruginosa in our community may be related to the rise of burn and wound patients than other samples in our population; which may be the result of different increased kitchen accidents, terrorist incidents, and electrical fire ${ }^{(18)}$.

\section{Conclusion}

Pseudomonas aeruginosa was isolated in relatively considerable number; consequently, much work is needed to overcome and control this opportunistic pathogen.

\section{Conflict of Interest: None}

\section{Funding: Self}

Ethical Clearance: Not required

\section{References}

1. Razzaq AA, Mahmood AK, Hammed NM, Jasim KA, Abdulqader ZS, Al-Mathkhury HJF. Gentamicin enhances toxA expression in Pseudomonas aeruginosa isolated form cow mastitis. Advances in Animal and Veterinary 
Sciences. 2018;6(12).

2. Granato ET, Ziegenhain C, Marvig RL, Kümmerli $\mathrm{R}$. Virulence evolution in the opportunistic bacterial pathogen Pseudomonas aeruginosa. 2018.

3. Pang Z, Raudonis R, Glick BR, Lin TJ, Cheng Z. Antibiotic resistance in Pseudomonas aeruginosa: mechanisms and alternative therapeutic strategies. Biotechnol Adv. 2019;37(1):177-92.

4. Davies J. Inactivation of antibiotics and the dissemination of resistance genes. Science. 1994;264(5157):375-82.

5. Khalil MA, Ibrahim Sonbol F, Mohamed AF, Ali SS. Comparative study of virulence factors among ESbetaL-producing and nonproducing Pseudomonas aeruginosa clinical isolates. Turk J Med Sci. 2015;45(1):60-9.

6. Amoon RH, Abdallha AH, Sharif AO, Moglad $\mathrm{EH}$, Altyb HN, Elzaki SG, et al. Molecular characterization of Pseudomonas aeruginosa isolates from Sudanese patients: A cross-sectional study. F1000Research. 2018;7:1135.

7. Pachori P, Gothalwal R, Gandhi P. Emergence of antibiotic resistance Pseudomonas aeruginosa in intensive care unit; a critical review. Genes Dis. 2019;6(2):109-19.

8. AL-Sheikhly M, Musleh L, Al-Mathkhury HJF. Assessment of pelA-carried Pseudomonas aeruginosa isolates in respect to biofilm formation. Iraqi Journal of Science. 2019;60:1180-7.

9. Spilker T, Coenye T, Vandamme P, LiPuma JJ. PCR-based assay for differentiation of Pseudomonas aeruginosa from other Pseudomonas species recovered from cystic fibrosis patients. J Clin Microbiol. 2004;42(5):2074-9.

10. Wilfinger WW, Mackey K, Chomczynski P. Effect of $\mathrm{pH}$ and ionic strength on the spectrophotometric assessment of nucleic acid purity. Biotechniques. 1997;22(3):474-6, 8-81.

11. Negi KS. Method in biostatistics. 1st ed. INDIA: AITBS publishers; 2012.

12. Lima J, Alves LR, Jacome P, Bezerra Neto JP, Maciel MAV, Morais MMC. Biofilm production by clinical isolates of Pseudomonas aeruginosa and structural changes in LasR protein of isolates non biofilm-producing. Braz $\mathrm{J}$ Infect Dis. 2018;22(2):129-36.

13. Al-Sheikhly MARH, Musleh LN, Al-Mathkhury HJF. Gene Expression of pelA and pslA in Pseudomonas Aeruginosa under Gentamicin Stress. Iraqi Journal of Science. 2020:295-305.

14. AL-Sheikhly M, Musleh L, Al-Mathkhury H. Distribution of pslA among Local Isolates of Biofilm-Producing Pseudomonas aeruginosa International Journal of pharmaceutical research. 2019;11(2):16-20.

15. Al-Derzi N. Pattern of Resistance to Pseudomonas infection in the North of Iraq: Emphasis on the Potential Role of a Combination Antibiogram. Iraqi Journal of Community Medicine. 2012;2:130-5.

16. Shilba A, Al-Azzawi R, Al-Awadi S. Dissemination of Carbapenem Resistant Pseudomonas aeruginosa among Burn Patients in Karbala Provincel Iraq. Iraqi Journal of Science. 2015;56:1850-7.

17. Hasan S, Najati A, Abass K. Prevalence and antibiotic resistance of "pseudomonas aeruginosa" isolated from clinical samples in Kirkuk City, Iraq. EurAsian Journal of BioSciences. 2020;14:1821-5.

18. Al-Ahmad A, Ameen H, Pelz K, Karygianni L, Wittmer A, Anderson AC, et al. Antibiotic resistance and capacity for biofilm formation of different bacteria isolated from endodontic infections associated with root-filled teeth. J Endod. 2014; 40(2):223-30. 